\title{
Effect of Valerian Extract Preparation (BIM) on the Sleep-Wake Cycle in Rats
}

\author{
Shin Tokunaga, ${ }^{a}$ Yasuhiro Takeda, ${ }^{a}$ Tsuyoshi Nimmoto, ${ }^{b}$ Norihisa Nishida, ${ }^{b}$ Toshihiro Kubo, ${ }^{b}$ \\ Tohru Ohno, ${ }^{b}$ Youichi Matsuura, ${ }^{b}$ Yuzo Kawahara, ${ }^{b}$ Kazuaki Shinomiya, ${ }^{c}$ and Chiaki Kamei ${ }^{*} a$ \\ ${ }^{a}$ Department of Medicinal Pharmacology, Okayama University Graduate School of Medicine, Dentistry and \\ Pharmaceutical Sciences; 1-1-1 Tsushima-naka, Okayama 700-8530, Japan: ${ }^{b}$ Morishita Jintan Co., Ltd.; 1-1-30 \\ Tamatsukuri, Chuo-ku, Osaka 540-8566, Japan: and ${ }^{c}$ Department of Pharmaceutical Care and Health Sciences, Faculty \\ of Pharmaceutical Sciences, Okayama University; 1-1-1 Tsushima-naka, Okayama 700-8530, Japan. \\ Received July 25, 2006; accepted November 7, 2006
}

In the present study, we studied the effect of valerian extract preparation (BIM) containing valerian extract, golden root (Rhodiola rosea $L$.) extract and L-theanine ( $\gamma$-glutamylethylamide) on the sleep-wake cycle using sleep-disturbed model rats in comparison with that of valerian extract. A significant shortening in sleep latency was observed with valerian extract and the BIM at a dose of $1000 \mathrm{mg} / \mathrm{kg}$. On the other hand, valerian extract and the BIM caused no significant effects on total times of wakefulness, non-rapid eye movement (non-REM) sleep and REM sleep. Valerian extract and the BIM at a dose of $1000 \mathrm{mg} / \mathrm{kg}$ also had no significant effect on delta activity. In conclusion, it became clear that the BIM could be useful as a herbal medicine having a sleep-inducing effect without causing an alteration of the sleep-wakefulness cycle.

Key words valerian extract preparation (BIM); valerian extract; sleep latency; sleep-disturbed model; insomnia; sleep quality

One out of 5 people has some form of sleep disorder in Japan. ${ }^{1)}$ Insomnia is not a trivial complaint, as it can produce impairments in daytime functioning, reduce the quality of life and increase health-care costs. ${ }^{2,3)}$ In spite of significant progress being made in the treatment of insomnia in recent years, ${ }^{4-6)}$ only a small proportion of those who suffer from insomnia actually receive professional treatment. Many people with insomnia do not wish to use actively hypnotic drugs, because these drugs show some side effects and carry the risk of tolerance and dependence. As a result, there is an increasing interest in the use of complementary and alternative medicines, such as herbal supplements, ${ }^{7-9)}$ partly because of their natural properties and perceived relative absence of residual effects.

Valerian extract, an herbal product consisting of the root of Valeriana officinalis L., is widely available on the market as a traditional medicine for the treatment of insomnia and anxiety. A considerable amount of research has been reported on the sleep of valerian extract in animals and humans. ${ }^{8-12)}$ Most of the evidence from randomized clinical trials, with repeated administration, suggests that valerian extract produces mild sleep-inducing effects, without causing alteration of the sleep architecture or significant residual effects. ${ }^{8,9,11,13)}$ There exists some literature on the valerian combined with other herbal extracts, such as hops, balm or passionflower. ${ }^{14-16)}$ However, there have been no reports on the effect of valerian when combined with golden root and L-theanine on the sleep-wake cycle in animals. Golden root (Rhodiola rosea L.) is a medicinal plant from the Crassulaceae family and is grown in dry and sandy ground, mainly in the Arctic and Alpine regions of the Europe, Asia and America. It has a long tradition as a medicinal plant with anti-fatigue action under stressful conditions in several European countries. ${ }^{17,18)}$ L-Theanine ( $\gamma$-glutamylethylamide) is a unique amino acid presented almost exclusively in the tea plant. It has been reported that $\mathrm{L}$-theanine has a great contribution to the taste of green tea, and is synthesized in the root of the plant. L-Theanine was discovered as a constituent of green tea in 1949 by Sakato, ${ }^{19}$ and in 1964 was approved as a food additive in Japan. Recently, the relaxing activity of green tea has been widely accepted throughout the world.

In a previous study, we developed a sleep-disturbed model that was useful for evaluating hypnotic potencies by placing rats on a grid suspended over water. ${ }^{20,21)}$ The hypnotic effects of some drugs in rats placed on the grid suspended over water were more potent than that in rats placed on sawdust. In the present study, therefore, we studied the hypnotic activities of the valerian extract preparation (BIM) which is a dietary supplement composed of valerian extract, golden root extract and L-theanine on the sleep-wake cycle using the sleep-disturbed model.

\section{MATERIALS AND METHODS}

Animals Male Wistar rats weighting 230-310 g (Japan SLC, Shizuoka, Japan) were used. All animals were maintained in an air-conditioned room with controlled temperature $\left(24 \pm 2{ }^{\circ} \mathrm{C}\right)$ and humidity $(55 \pm 15 \%)$. They were housed in aluminum cages with sawdust and kept under a light-dark cycle (lights on from 7:00 to 19:00). The animals were allowed free access to food and water, except during the experiments. All procedures involving animals were conducted in accordance with the guidelines for animal experiments at Okayama University Advanced Science Research Center.

Surgery The animals were anesthetized with pentobarbital sodium (Nembutal ${ }^{\circledR}, 35 \mathrm{mg} / \mathrm{kg}$, i.p., Abbott Laboratories, North Chicago, IL, U.S.A.) and then placed in a stereotaxic apparatus (SR-5, Narishige, Tokyo, Japan). For electroencephalogram (EEG) recording, a stainless steel screw electrode was chronically implanted into the right frontal cortex (A: 0.5 , L: 3.0) according to the atlas of Paxinos and Watson. $^{22)}$ To record the electromyogram (EMG), we implanted stainless steel wire electrodes $(200 \mu \mathrm{m})$ into the dorsal neck muscle. A stainless steel screw fixed in the left 


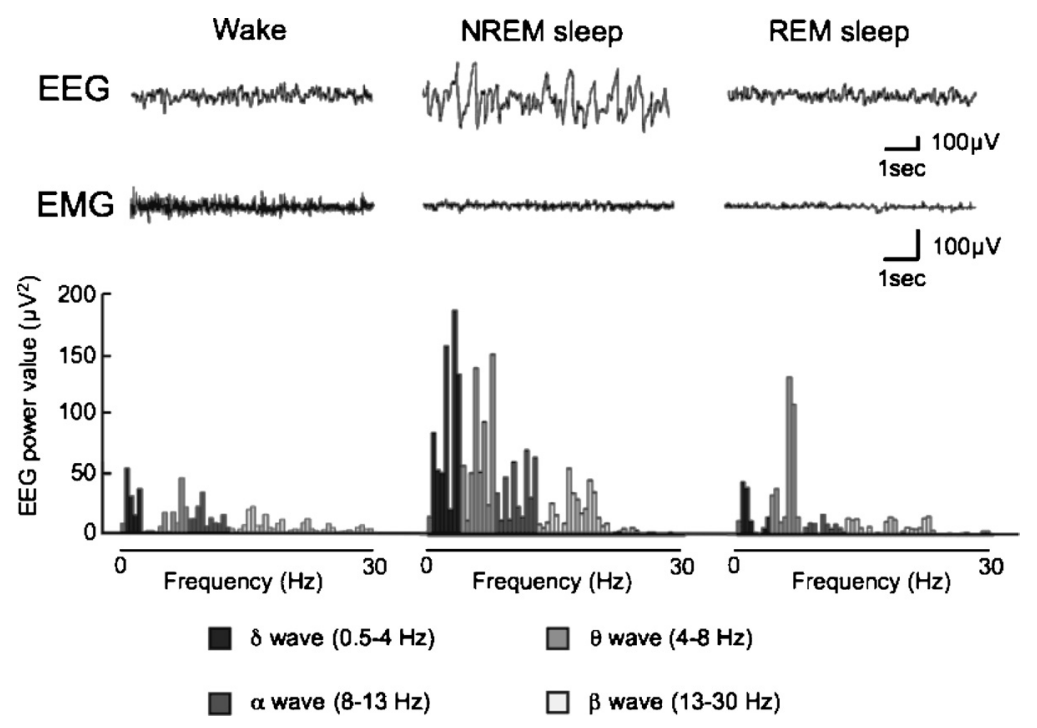

Fig. 1. Representative EEG, EMG and EEG Power Value in Rats during Wakefulness, Non-REM Sleep and REM Sleep

frontal bone served as a reference electrode. The electrodes were connected to a miniature receptacle, and the whole assembly was fixed to the skull with dental cement. At least $7 \mathrm{~d}$ were allowed for recovery from the surgery.

EEG and EMG Recordings EEG and EMG were recorded with an electroencephalograph (Model EEG 5113, Nihon Kohden, Tokyo, Japan) from 9:00 to 15:00. The recording was carried out according to the method described previously. ${ }^{21,23)}$ The signals were amplified and filtered (EEG, $0.5-30 \mathrm{~Hz}$; EMG, $16-128 \mathrm{~Hz}$ ), then digitized at a sampling rate of $128 \mathrm{~Hz}$ and recorded using the data acquisition program SleepSign ver.2.0 (Kissei Comtec, Nagano, Japan). The EEG and EMG were measured in a cylindrical plastic cage (diameter, $26 \mathrm{~cm}$; height, $31 \mathrm{~cm}$ ). A grid floor was placed inside the plastic cage. The cage was filled with water up to $1 \mathrm{~cm}$ below the grid surface. The stainless steel rods of the grid ( $3 \mathrm{~mm}$ wide) were set $2 \mathrm{~cm}$ apart from each other. The observation cage was placed in a sound-proof and electrically-shielded box $(70 \times 60 \times 60 \mathrm{~cm})$.

Sleep-Wake State Analysis The sleep-wakefulness states were automatically classified by 10 -s epochs as wakefulness, non-rapid eye movement (non-REM) and REM sleep by SleepSign ver.2.0 according to the criteria previously described. ${ }^{20,24)}$ The power spectrum densities, integrated and averaged, could be divided into 4 frequency areas: delta wave $(0.5-4 \mathrm{~Hz})$, theta wave $(4-8 \mathrm{~Hz})$, alpha wave $(8-13 \mathrm{~Hz})$ and beta wave $(13-30 \mathrm{~Hz})$. The sleep-wakefulness state was characterized as follows: wakefulness, low-amplitude EEG (delta, theta, alpha and beta waves) and high-voltage EMG activities; non-REM sleep, high-amplitude slow or spindle EEG (delta, theta, alpha and beta waves) and low-EMG activities; REM sleep, low-voltage EEG (except for theta wave) and EMG activities (Fig. 1).

Calculation for Delta Activities during Non-REM Sleep The delta activity $(0.5-4 \mathrm{~Hz})$ during non-REM sleep was determined using a program of SleepSign ver.2.0. The data of delta power in non-REM sleep were expressed as a percentage of the average delta activity in non-REM sleep during the entire recording period of each control group.

Drugs Valerian extract and BIM, containing $400 \mathrm{mg}$ of valerian extract, $100 \mathrm{mg}$ of golden root extract and $50 \mathrm{mg}$ of L-theanine, were provided by Morishita Jintan Co., Ltd. (Osaka, Japan). The ethanolic extracts from the roots of Valeriana officinalis $\mathrm{L}$. and Rhodiola rosea $\mathrm{L}$. were extracted with $70 \%$ ethanol. These extracts were concentrated and spray-dried with $8 \%$ or $2 \%$ maltodextrin and $1 \%$ silicon dioxide. L-Theanine was purchased from Wako Pure Chemical Industries, Ltd. (Osaka, Japan). The preparation was dissolved in water and administered orally at 9:00, and EEG and EMG were measured for $6 \mathrm{~h}$ after drug administration. Eight rats were used in each group, and a counterbalanced design for drug dosage was used. Drugs were administered at intervals of $7 \mathrm{~d}$ when the same rats were used for repeated experiments. Each rat was subjected to experimentation 4 times.

Data Analysis and Statistics Values shown are means \pm S.E.M. Statistical analyses were performed using the software Dr. SPSS II (Nankodo Co., Ltd., Tokyo, Japan). One-way analysis of variance (ANOVA) with the Scheffe test was used for estimating the drug effects. Sleep latency was defined as the time from drug administration up until the first 12 consecutive 10-s epochs of sleep.

\section{RESULTS}

Effects on Sleep Latency Both valerian extract and the BIM caused a dose-dependent decrease in sleep latency. A significant shortening of sleep latency was observed at a dose of $1000 \mathrm{mg} / \mathrm{kg}$ for each drug. The potency of the BIM is somewhat less potent than that of valerian extract (Fig. 2).

Effect on Sleep Parameters Valerian extract caused no significant effects on total time of wakefulness, non-REM sleep and REM sleep, even at a dose of $1000 \mathrm{mg} / \mathrm{kg}$. The BIM at a dose of $1000 \mathrm{mg} / \mathrm{kg}$ also had no significant effects on the total times of wakefulness, non-REM sleep and REM sleep (Fig. 3).

Effects on Delta Activity during Non-REM Sleep Both valerian extract and the BIM caused no significant effects at a dose of $1000 \mathrm{mg} / \mathrm{kg}$ of each drug on the delta activity during non-REM sleep (Table 1). 
Table 1. Effects of Valerian Extract and the Valerian Extract Preparation on Delta Activity during Non-REM Sleep in Sleep-Disturbed Rats

\begin{tabular}{|c|c|c|c|c|c|c|}
\hline \multirow{2}{*}{ Dose $(\mathrm{mg} / \mathrm{kg}$, p.o. $)$} & \multicolumn{6}{|c|}{ EEG activity (\% of control) } \\
\hline & $0-1$ & $1-2$ & $2-3$ & $3-4$ & $4-5$ & $5-6(h)$ \\
\hline \multicolumn{7}{|l|}{ Valerian extract } \\
\hline Control & $100.0 \pm 10.7$ & $100.0 \pm 11.4$ & $100.0 \pm 9.2$ & $100.0 \pm 8.2$ & $100.0 \pm 7.2$ & $100.0 \pm 8.7$ \\
\hline 300 & $107.4 \pm 8.2$ & $102.9 \pm 8.7$ & $124.1 \pm 16.6$ & $87.2 \pm 11.5$ & $95.7 \pm 12.2$ & $91.2 \pm 12.6$ \\
\hline 1000 & $98.9 \pm 8.1$ & $102.9 \pm 14.4$ & $116.0 \pm 16.5$ & $99.6 \pm 13.0$ & $113.9 \pm 12.3$ & $116.0 \pm 14.7$ \\
\hline \multicolumn{7}{|c|}{ Valerian extract preparation } \\
\hline Control & $100.0 \pm 18.0$ & $100.0 \pm 18.4$ & $100.0 \pm 15.4$ & $100.0 \pm 17.6$ & $100.0 \pm 13.5$ & $100.0 \pm 14.9$ \\
\hline 100 & $65.0 \pm 10.3$ & $73.6 \pm 13.6$ & $90.1 \pm 12.6$ & $94.6 \pm 9.8$ & $81.8 \pm 12.5$ & $75.6 \pm 11.4$ \\
\hline 300 & $80.7 \pm 12.7$ & $82.8 \pm 17.2$ & $100.6 \pm 14.7$ & $108.3 \pm 17.2$ & $88.1 \pm 18.0$ & $91.2 \pm 12.2$ \\
\hline 1000 & $111.8 \pm 24.2$ & $105.5 \pm 19.4$ & $120.7 \pm 26.7$ & $118.7 \pm 28.4$ & $109.2 \pm 29.5$ & $114.9 \pm 26.7$ \\
\hline
\end{tabular}

Values represent means \pm S.E.M. $(n=7 — 8)$. Drugs were administered orally.
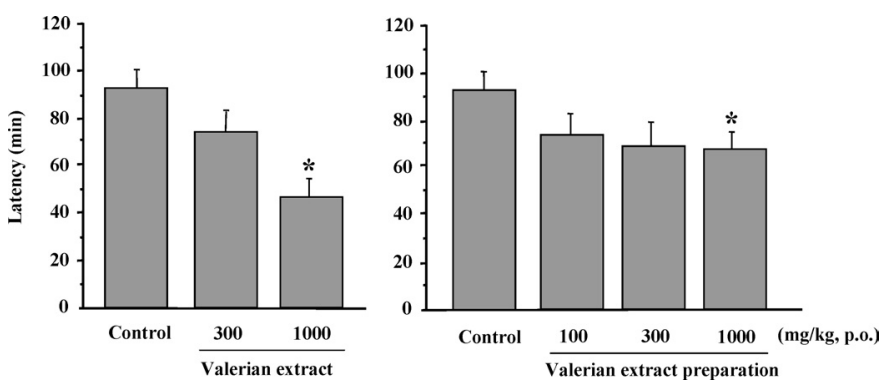

Fig. 2. Effects of Valerian Extract and the Valerian Extract Preparation on Sleep Latency in Sleep-Disturbed Rats

Columns and vertical bars represents the mean \pm S.E.M. $(n=7-8)$. Drugs were administered orally. $*$ Significantly different from control group at $p<0.05$.

\section{DISCUSSION}

In the present study, it was found that both valerian extract and the BIM caused a significant shorting of sleep latency. In a previous study, we reported that valerian extract at doses of 1000 and $3000 \mathrm{mg} / \mathrm{kg}$ showed a significant shortening in sleep latency in the sleep-disturbed rat model. ${ }^{25}$ ) That is to say, reproducible results were obtained with valerian extract. On the other hand, the BIM showed a lower effect on sleep latency compared with the same dose of valerian extract. The BIM is a combined drug consisting of the valerian extract, golden root and L-theanine $(4: 1: 0.5)$. Moreover, there are no reports that golden root and L-theanine are effective for sleep latency. Therefore, it is reasonable to presume that the effect on sleep latency of the BIM may be attributable to the presence of not golden root and L-theanine but valerian extract. It had been reported that golden root and L-theanine had an anti-fatigue effect ${ }^{17,18)}$ and relaxing activity, respectively. From these findings, however, it was revealed that these effects were not involved in sleep inducing-effect of the BIM.

Next, to clarity whether the BIM shows an effect on the other sleep parameters, the total times of wakefulness, nonREM sleep and REM were measured. As a result, no observable effects were obtained with the BIM in total times of each sleep state same as the valerian extract. In addition, similar to valerian extract, the BIM also caused no significant changes on the delta activity, which is an indicator of sleep quality. The detailed mechanisms of valerian extract, which is the major proportion in the BIM, with regard to the hypnotic effect are not yet clear. Santos et al. ${ }^{26,27)}$ reported that

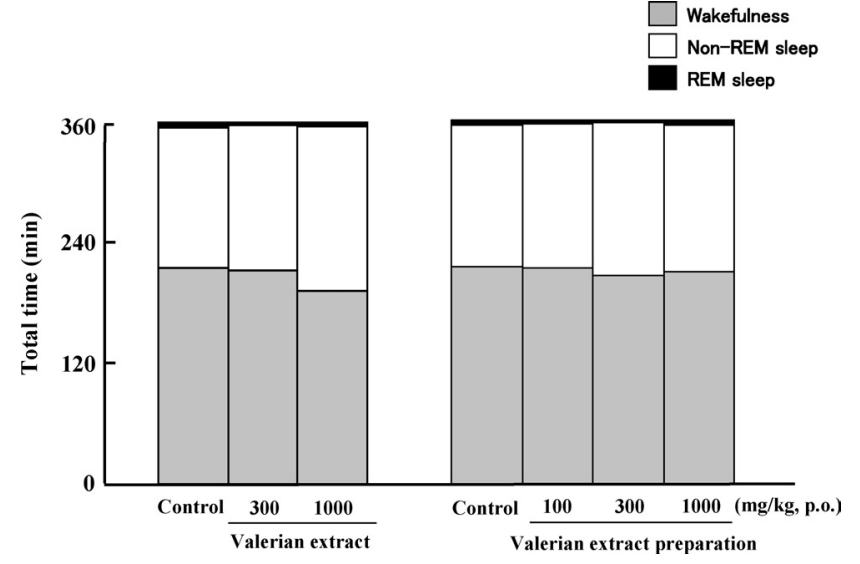

Fig. 3. Effects of Valerian Extract and the Valerian Extract Preparation on the Total Time of Each Sleep State in Sleep-Disturbed Rats

Columns represents the mean of each sleep time $(n=7-8)$. Drugs were administered orally, and EEG and EMG were measured for $6 \mathrm{~h}$.

an aqueous extract of valerian inhibited $\left({ }^{3} \mathrm{H}\right) \gamma$-aminobutyric acid (GABA) uptake and induced the $\mathrm{Ca}^{2+}$-independent release of $\left({ }^{3} \mathrm{H}\right)$-GABA. Ortiz et al. ${ }^{28)}$ also reported that valerian extract increased both $\mathrm{K}^{+}$- and veratridine-stimulated $\left({ }^{3} \mathrm{H}\right)$ GABA release and caused the inhibition of $\left({ }^{3} \mathrm{H}\right)$-GABA uptake. From these findings, it seems likely that the extracellular GABA level increased by valerian extract resulted in the hypnotic effects.

In conclusion, the BIM may be useful as a treatment for insomnia without causing an alteration of the sleep-wake cycle. On the other hand, the detailed mechanisms of the hypnotic effects of the BIM are not yet clear. Further research will be needed to examine the possibility of its safety and health benefits.

\section{REFERENCES}

1) Kim K., Uchiyama M., Okawa M., Liu X., Ogihara R., Sleep, 23, 4147 (2000).

2) Leger D., Scheuermaier K., Philip P., Paillard M., Guilleminault C., Psychosom. Med., 63, 49-55 (2001).

3) Simon G. E., VonKorff M., Am. J. Psychiatry, 154, 1417-1423 (1997).

4) Morin C. M., Hauri P. J., Espie C. A., Spielman A. J., Buysse D. J., Bootzin R. R., Sleep, 22, 1134-1156 (1999).

5) Nowell P. D., Mazumdar S., Buysse D. J., Dew M. A., Reynolds C. F., Kupfer D. J., JAMA, 278, 2170-2177 (1997).

6) Smith M. T., Perlis M. L., Park A., Smith M. S., Pennington J., Giles D. E., Buysse D. J., Am. J. Psychiatry, 159, 5-11 (2002). 
7) Eisenberg D. M., Davis R. B., Ettner S. L., Apple S., Wilkey S., Rompay M. V., Kessler R. C., JAMA, 280, 1569-1575 (1998).

8) Gyllenhaal C., Merritt S. L., Peterson S. D., Block K. I., Gochenour T., Sleep Med. Rev., 4, 229-251 (2000).

9) Meoli A. L., Rosen C., Kristo D., Kohrman M., Gooneratne N., Aguillard R. N., Fayle R., Troell R., Touwnsend D., Claman D., Hoban T., Mahowald M., J. Clin. Sleep Med., 1, 173-187 (2005).

10) Houghton P. J., J. Pharm. Pharmacol., 51, 505-512 (1999).

11) Stevinson C., Ernst E., Sleep Med., 1, $91-99$ (2000).

12) Wong A. H. C., Smith M., Boon H. S., Arch. Gen. Psychiatry, 55, 1033-1044 (1998).

13) Hallam K. T., Olver J. S., McGrath C., Norman T. R., Hum. Psychopharmacol., 18, 619-625 (2003).

14) Cerny A., Schmid K., Fitoterapia, 70, 221-228 (1999).

15) Lindahl O., Lindwall L., Pharmacol. Biochem. Behav., 32, 10651066 (1989).

16) Schmitz M., Jackel M., Wien. Med. Wochenschr., 13, 291-298 (1989).

17) Darbinyan V., Kteyan A., Panossian A., Gabrielian E., Wikman G., Wagner H., Phytomedicine, 7, 365-371 (2000).

18) Shevtsov V. A., Zholus B. I., Shervarly V. I., Vol'skij V. B., Korovin Y. P., Khristich M. P., Roslyakova N. A., Wikman G., Phytomedicine, 10,
95-105 (2003).

19) Sakato Y., Nippon Nogeikagaku Kaishi, 23, 262-267 (1949).

20) Shinomiya K., Shigemoto Y., Okuma C., Mio M., Kamei C., Eur. J. Pharmacol., 460, 139-144 (2003).

21) Shinomiya K., Shigemoto Y., Omichi J., Utsu Y., Mio M., Kamei C., Psychopharmacology, 173, 203-209 (2004).

22) Paxinos G., Watson C., "The Rat Brain in Stereotaxic Coordinates," Academic Press, San Diego, 1986.

23) Huang Z. L., Qu W. M., Li W. D., Mochizuki T., Eguchi N., Watanabe T., Urade Y., Hayashi O., Proc. Natl. Acad. Sci. U.S.A., 98, 99659970 (2001).

24) Shigemoto Y., Shinomiya K., Mio M., Azuma N., Kamei C., Eur. J. Pharmacol., 494, 161-165 (2004).

25) Shinomiya K., Fujimura K., Kim Y., Kamei C., Acta Med. Okayama, 59, 89-92 (2005).

26) Santos M. S., Ferreria F., Cunha A. P., Carvalho A. P., Macedo T., Planta Med., 60, 278-279 (1994).

27) Santos M. S., Ferreria F., Cunha A. P., Carvalho A. P., Riberio C. F. Macedo T., Arch. Int. Pharmacodyn. Ther, 327, 220-231 (1994).

28) Ortiz J. G., Nieves-Natal J., Chavez P., Neurochem. Res., 24, 13731378 (1999). 